\title{
Arteterapia Gestalt: "La búsqueda de lo que somos"
}

\author{
Marina OJEDA LÓPEZ ${ }^{1}$ \\ marinaojeda_arteterapia@hotmail.com
}

Enviado: 21/03/2011

Aceptado: 12/10/2011

RESUMEN.

El Arteterapia gestalt abre una interesante vía para acceder a la subjetividad de la persona, a sus cuestiones inconclusas que se actualizan aquí y ahora a través de la obra. En nuestras creaciones materializamos nuestras necesidades más apremiantes y significativas. Así se establece un diálogo de la persona consigo misma, permitiendo que nuestras imágenes internas salgan a la luz. Ellas nos cuentan y nos encauzan en un camino de autodescubrimiento, ampliando nuestra mirada y nuestras posibilidades de vivir una vida más sana y más plena.

Palabras clave: Arteterapia gestalt, aquí y ahora, responsabilidad, conciencia, imágenes internas.

\section{Referencia normalizada}

OJEDA LÓPEZ, M. (2011). “Arteterapia Gestalt: "La búsqueda de lo que somos". En Arteterapia: Papeles de arteterapia y educación artística para la inclusión social Vol.: 6. Páginas 169-181. Madrid. Servicios de publicaciones UCM.

\section{SUMARIO}

Introducción. La gestalt. De dónde surge. Aspectos clave en Arteterapia Gestalt. Otros recursos en Arteterapia gestalt. El encuadre en Arteterapia gestalt. Arteterapia gestalt. Cómo trabajamos con nuestras imágenes internas. Conclusión. Referencias bibliográficas

\section{Gestalt Art Therapy: "Searching as we are"}

\begin{abstract}
.
Gestalt Art therapy opens an interesting way to access the human subjectivity, to their unfinished questions, which are brought up to date here and now throw the artistic work. In our creations we materialize our urgent and meaningful needs. So, the person establishes a dialogue himself, allowing our internal images to come up. They tell us and guide us into a self-discovery way, widening our look and our possibilities of living a healthier and fuller life.
\end{abstract}

Keywords: Gestalt Art-therapy, here and now, responsibility, consciousness, internal images.

\section{CONTENTS}

Introduction. The Gestalt. Where does it comes from?. Key facts in Gestalt Art Therapy. Other resources in gestalt Art Therapy. The setting in gestalt Art Therapy. Gestalt Art Therapy. How we manage our inner images?. Conclusion. References

\footnotetext{
${ }^{1}$ Arteterapeuta por la Universidad Complutense de Madrid.
} 


\section{INTRODUCCIÓN}

Ante la invitación de AFIA de dar comienzo a las Jornadas de Formación Continua con una charla, me planteé qué era lo que podía aportar. Buscando dentro de mí, me di cuenta de que la mejor manera de transmitir algo es vivirlo, experimentarlo en primera persona y, a partir de ahí, volcarlo fuera, compartirlo con otras personas que puedan estar en una búsqueda parecida a la propia. Desde que terminé el Máster de Arteterapia en la Universidad Complutense de Madrid, he seguido indagando, formándome y ampliando conocimientos y sobre todo experiencia, la experiencia de vivir.

Cada cual se identifica con una u otra corriente terapéutica en función de su afinidad con los diversos planteamientos y maneras, pero también es el carácter de la persona, su forma de gestionar su vida y las relaciones humanas lo que nos hace elegir uno u otro camino. Para mí la gestalt está siendo no sólo un marco en el que me ubico profesionalmente, sino también una experiencia viva, una manera de encontrarme conmigo misma y de crecer. La formación en terapia gestalt va acompañada de un largo y profundo proceso de desarrollo personal en el que el grupo juega un papel muy importante como reflejo de esos procesos de cambio internos que desde el comienzo empiezan a generarse. Paralelamente, la oportunidad de trabajar conmigo misma en terapia individual me hace profundizar en mi propio camino y al mismo tiempo me permite aplicar lo aprendido desde mí, para poder construir una manera coherente de trabajo con los otros.

Nadie puede acompañar a otra persona en un proceso de duelo si no lo ha vivido, al igual que no puede comprender el dolor y la angustia de otros ante las dificultades de la vida si no ha sido capaz de transitar su propio malestar y su angustia.

Para mí la Gestalt es una vía de reencuentro con mi esencia, una manera de destapar y dejar salir a la luz a esa otra persona que antes no conocía y que ahora quiero acoger y escuchar.

$\mathrm{Y}$ esto es en principio lo que me impulsa a llevar la Gestalt a mi trabajo desde el Arteterapia. Saber que si para mí es útil y enriquecedor, también lo puede ser para otras personas en su proceso de encontrarse y descubrirse.

La Gestalt es una corriente de la psicoterapia humanista que facilita el despertar de la conciencia y que abre un camino para la búsqueda de la verdadera identidad. El Arteterapia gestáltica ofrece posibilidades para acceder a la subjetividad de la persona y sus problemáticas, favoreciendo el contacto con sus potencialidades y necesidades más auténticas.

En mi charla pude compartir una metodología de trabajo basada en los aspectos clave de la terapia Gestalt aplicados al Arteterapia, dando forma así a una disciplina amplia y rica que plantea el trabajo de desarrollo personal de una manera holística e integradora, donde el arte, el cuerpo y la palabra favorecen la expresión y la integración de los aspectos menos conocidos de nosotros mismos. 


\section{LA GESTALT. DE DÓNDE SURGE}

La terapia de la gestalt procede la la psicología de la Gestalt o psicología de la forma que surgió con los psicólogos alemanes de principios del S.XX Koffka, Köhler, Wertheimer, entre otros. Partían del fenómeno como totalidad. Como ellos defendieron, si queremos estudiar un fenómeno a partir de sus partes, en cuanto lo fragmentamos para estudiarlo, lo destruimos. Tenemos la tendencia a organizar cualquier campo visual en totalidades o figuras globales y no a percibir los fenómenos aislados unos de otros.

Surge el concepto de campo. Todo ocurre dentro de un campo o contexto y los elementos están relacionados ya que todo influye sobre todo, en función de la proximidad de los campos y los elementos. No son, por tanto los elementos que hay que estudiar, sino la disposición entre esos elementos, el cómo y no el porqué.

Fritz Perls introduce el concepto de motivación y la emocionalidad en la percepción de la teoría de la gestalt, dando lugar a la psicoterapia gestáltica. Se comienza a entender al individuo como un todo, donde el organismo y el ambiente, forman parte de la persona y cada una de estas partes están vinculadas e íntimamente relacionadas. Por tanto la conducta depende de la capacidad del organismo de satisfacer sus necesidades sin oponerse de una manera radical o violenta a las demandas del mundo externo.

En el contexto arteterapéutico el campo lo conforman todos los elementos que intervienen en esa relación triangular entre la obra, el arteterapeuta y la persona que crea. Ahí está todo, el material, la creación en sí, la simbología de lo representado; el arteterapeuta con sus propias vivencias, recursos y su emocionalidad; y la persona con todas sus necesidades, miedos y deseos.

El concepto figura-fondo también es importante. La figura es lo que emerge del campo, lo que se manifiesta de una manera sobresaliente y tiene una forma definida. El fondo es lo que queda atrás, algo indefinido que sirve de base a la forma. La forma va asociada a nuestras necesidades, emociones y sentimientos y emerge en base a una carencia o una presión. En la obra hay multitud de elementos, pero sólo aquellos que implican una necesidad más apremiante en ese momento, son los que emergen para ser abordados. De pronto, algo se hace evidente, algo surge del fondo y comienza así ese proceso de diálogo que nos llevará a la búsqueda del equilibrio. Tenemos necesidades que necesitan ser satisfechas (figura). Una vez satisfechas de forma adecuada, son eliminadas y sustituidas por otras. Es un proceso evolutivo de continuo cambio y sucesión de gestalts. Cuando esas necesidades no son satisfechas, quedamos atrapados y enganchados y vamos arrastrando asuntos pendientes que nos paralizan en situaciones conflictivas. Por eso la creación en Arteterapia es un campo rico y fértil, donde trabajamos desde la subjetividad y también desde la objetividad que la obra nos muestra. En ese espacio intermedio es donde podemos probar, experimentar y ensayar pequeños cambios a través del material, del color, de la forma, para dar paso poco a poco a esa integración que buscamos. 


\section{ASPECTOS CLAVE EN TERAPIA GESTALT}

\section{AQUÍ Y AHORA. LA ACTUALIDAD TEMPORAL, ESPACIAL Y SUSTANCIAL}

"En gestalt intentamos evitar todo lo que no está o no se desarrolla en el presente, incluso si el conflicto que aparece hace referencia a una experiencia del pasado o a un temor del futuro, traemos este material al aquí y ahora, porque sólo en el presente se puede llevar a cabo la integración". Paco Peñarrubia.

La experiencia creativa en arteterapia nos permite actualizarnos constantemente porque el acto de crear se produce aquí y ahora y en él materializamos todo lo que necesita ser abordado o trabajado. Al crear algo necesitamos poner toda nuestra atención, nuestros sentidos en lo que sentimos o lo que emerge en la obra que tiene que ver con nuestro pasado, todos nuestros dolores, resentimientos, carencias. También en lo sentimos ahora, en las cuestiones inconclusas que son traídas al presente para poder ser trabajadas e integradas. Sólo tenemos el momento presente y en él es donde podemos retomar, rehacer, re-escribir o recrear nuestra vida. Se trata de ir entrando en contacto poco a poco con nuestros recursos, con nuestras potencialidades y con nuestra necesidad de ser nosotros mismos. Lo mismo ocurre con el futuro. Lo que tememos o deseamos, necesita ser abordado en el presente. El miedo ocurre ahora, el deseo también.

El pasado es importante en la medida en que interfiere en mi presente, ya que todo lo que no está en su lugar, todo lo que no está integrado, vuelve bajo diferentes formas y circunstancias para poder ser elaborado.

A esto es lo que llamamos Gestalt inconclusa y tiene que ver con la formación de una Gestalt.

Desde que nacemos, todos tenemos necesidades que necesitan ser satisfechas, desde el comer, la protección, hasta la más importante para nuestro desarrollo: el amor. Aquí y ahora es el momento de actualizar esas carencias y asuntos que no nos permiten articular nuestra vida de una manera sana.

Es en la obra donde actualizamos nuestra experiencia, donde emerge todo aquello que cobra importancia y sobre lo que podemos intervenir.

\section{LA ATENCIÓN Y LA ACEPTACIÓN DE LA EXPERIENCIA. EL DARSE CUENTA}

Si conectamos con nuestro interior, en la obra comienzan a aparecer imágenes que buscan salir a la luz. Dar forma a todo aquello que necesita salir a la superficie, nos pone en contacto con la experiencia de Ser. El darse cuenta es un eje vertebrador de la terapia gestalt. Es poner conciencia en nosotros y la obra nos lo muestra de frente, si la dejamos surgir de forma espontánea y flexible.

El darse cuenta no es solamente observar. Existe un darse cuenta interno, que tiene que ver con nuestras sensaciones que se materializan en nuestro cuerpo, los sentimientos que emergen, nuestra respiración. Existe también un darse cuenta de lo externo, de lo obvio, lo más objetivo, lo que aparece en la obra tal cual, lo que observo, lo que es. Y existe por último un darse cuenta de nuestra zona intermedia, 
aquella zona de nuestros pensamientos, ideas, juicios, proyectos y expectativas. Esta zona intermedia muchas veces se convierte en una huída, en una manera de escapar a lo que sentimos profundamente y que nos asusta. A través de la racionalización evitamos el surgir de nuestras necesidades más profundas. Es importante por tanto, tratar de evitar el por qué, la búsqueda del motivo, y centrarnos más en el cómo, en lo que es, aquí y ahora.

\section{LA RESPONSABILIDAD. DE LA CONCIENCIA A LA ACCIÓN}

"Somos responsables de nosotros, querámoslo o no. La terapia gestalt acentúa la conciencia de esta realidad con una permanente invitación a que la persona se responsabilice de lo que está haciendo, sintiendo, evitando o negando, deseando, inhibiendo..." Paco Peñarrubia.

Cuando abordamos el trabajo en arteterapia, una de las mayores dificultades que encontramos es que la persona se haga cargo de lo propio. La identificación con la obra es la identificación con uno mismo. Es fundamental que aceptemos lo nuestro, lo extraño, lo desconocido, lo monstruoso, lo desagradable. Hemos aprendido a apoyarnos en el otro para que resuelva o haga lo que no nos sentimos capaces de hacer por nosotros mismos. Cuando creamos somos nosotros los artífices de la obra, los protagonistas de nuestra vida-obra.

Es fundamental devolver a la persona la capacidad de confiar en sí misma. En la mayoría de los casos de las personas que acuden a terapia esta confianza está rota o desgastada, y es en el encuentro triangular de la persona con la obra y el arteterapeuta donde se hace posible la recuperación de esta confianza. Confiar en la obra, darle una importancia, darle un lugar, es empezar a darnos un lugar a nosotros mismos, darnos espacio y tiempo para comenzar a mirarnos. Y confiar en lo que la obra muestra es un acto de valentía y de compromiso con uno mismo.

\section{ELEMENTOS CON LOS QUE TRABAJAMOS}

\section{LA COMUNICACIÓN EN GESTALT}

La escucha interna es la capacidad del escuchador, del arteterapeuta, de mirarse hacia dentro, estar atento a sus propias sensaciones y a los procesos que se le despiertan al mismo tiempo que está disponible para el otro. Es un usarse a sí mismo como herramienta.

La escucha externa implica un despertar de los sentidos y estar atento no sólo a lo que dice el otro, sino a cómo lo dice: los gestos, la postura, el tono de voz, la mirada, etc. Muchas veces encontramos que lo que está diciendo se contradice con cómo lo está diciendo. Los conflictos emocionales se enmascaran con las palabras, el cuerpo miente menos.

- En la comunicación es importante tener en cuenta hablar en primera persona y en presente, actualizando así la vivencia y haciéndonos cargo de ella.

- También es importante evitar las preguntas y convertirlas en afirmaciones. 
- Integrar en vez de disociar: $y$ en lugar de pero.

Con respecto a la respuesta gestáltica, lo adecuado es el equilibrio entre el apoyo y la confrontación: apoyar sus conductas, sus sentimientos y deseos genuinos y confrontarle con sus juegos neuróticos (lo falso, lo evitativo, lo manipulativo).

\section{POLARIDADES}

En la construcción de nuestra personalidad, hemos ido definiendo nuestro autoconcepto, dando forma a una imagen de nosotros que con el tiempo se hace estática y fija. Esa identificación con ciertos aspectos de nosotros mismos nos hace rígidos porque en esa afirmación de lo que sí somos, estamos negando muchos aspectos de nosotros mismos que no queremos ser, que no queremos aceptar como partes nuestras.

En la experiencia arteterapéutica se pone de manifiesto esa lucha constante que todos tenemos entre cómo deben ser las cosas, cómo me gustaría que fueran y cómo son realmente; entre lo que creo que soy y lo que se manifiesta de mí; entre lo que acepto y lo que rechazo; entre lo que dejo ver y lo que escondo.

En la obra entra en juego un rico diálogo entre nuestro lado más caótico, más loco, más extraño, temido e incómodo y nuestro lado más formal, aceptado, organizado y normalmente más rígido. En la experiencia creativa es posible volcar todas estar partes de nosotros sin juzgarlas, dándoles un lugar, permitiéndoles que sean y que se expresen para, a partir de ahí, encontrar poco a poco un espacio de integración.

Pero no debe existir a priori una propuesta de identificación porque entonces tenderemos a manipular la imagen y tendremos un excesivo control sobre ella, quedándonos en la explicación y justificación.

El trabajo con polaridades en arteterapia es un proceso lento en el que ir haciéndonos cargo de aspectos negados de uno mismo, haciéndonos poco a poco responsables de ellos, ampliando nuestra mirada. Es un juego, un "como sí" que nos permite cuestionarnos, replantearnos, ensayar nuevas maneras, otras posibilidades, sin sentirnos amenazados o invadidos.

MECANISMOS DE EVITACIÓN Y MECANISMOS NEURÓTICOS: INTROYECCIÓN, PROYECCIÓN, CONFLUENCIA, RETROFLEXIÓN, DEFLEXIÓN

Nuestro impulso hacia el crecimiento y nuestros deseos de sanar nuestras heridas van de la mano con el deseo de no volver a sufrir. Por eso en todo proceso arteterapéutico entran en juego los mecanismos de evitación.

Estos nos ayudan a protegernos y vienen de tiempo atrás, cuando de niños aprendimos a comportarnos de una u otra manera para no sufrir. Pero estos mecanismos se tornan en neuróticos cuando tratamos de escaparnos de forma crónica y reiterada de situaciones de peligro imaginarias.

En el encuentro en arteterapia poco a poco facilitamos un contexto de seguridad en el que la persona necesita protegerse cada vez menos y entra en contacto con sus recursos internos para hacer frente a la experiencia que está viviendo. Lo importante 
es validar lo que aparece en la obra, sin tratar de desmontar las defensas en un primer momento, sino acompañar a la persona con sus resistencias y sus síntomas. Cortar sus expresiones neuróticas dejaría a la persona bloqueada, sin la capacidad de actuar. Es necesario que ella se vaya reconociendo poco a poco en sus mecanismos y así podremos ir confrontándola con su obra para que ella vaya encarándola en la medida de sus posibilidades. Es ir levantando un nuevo pilar, un nuevo sostén basado en el autoconocimiento, la aceptación de uno mismo, la integración de nuestras luces y nuestras sombras. Y solamente cuando este pilar pueda sostener la estructura, será cuando podamos ir desmontando poco a poco el pilar de nuestras defensas, confrontándonos con nuestros juegos neuróticos.

Las introyecciones son actitudes, ideas, juicios, valores que no son nuestros y que incorporamos en nosotros sin digerir. Normalmente las personas que tienen fuertes introyectos buscan en la obra realizar algo muy concreto, algo que previamente tienen determinado y de una manera que consideran correcta. Suelen estar muy poco en contacto con sus verdaderas necesidades. El trabajo está en ayudar al otro a reconocer y a nombrar lo que hay, no lo que debería haber.

En la proyección ponemos fuera aquello que no consideramos aceptable en nosotros: sentimientos, ideas, acciones. Suele haber una gran presión interna y las obras suelen resultar inaceptables para el que las crea, producen rechazo y miedo. Y mucha desconfianza. Es importante trabajar la confianza antes de enfrentar a la persona con sus sentimientos no expresados y facilitar que la persona entre en contacto con esos espacios internos que no reconoce como propios.

La confluencia nos lleva a mezclarnos con el otro, incapaces de retirarnos, de ser por nosotros mismos. Hay poca conciencia del propio espacio, de las propias necesidades y deseos. Las obras suelen ser confusas, poco definidas y las personas que las realizan están muy alertas y complacientes de las "pautas" que solicitan constantemente al arteterapeuta. En estos casos es necesario fortalecer el juicio y la percepción de lo propio. Aprender a ver lo que necesita el cuadro, atender a lo obvio, lo externo, para poder luego hacerlo propio.

En la retroflexión dirigimos la actividad hacia dentro. Es necesario cambiar la dirección de la actividad de dentro a fuera, facilitar que la persona vuelque en la obra lo que normalmente vuelca hacia sí mismo en forma de somatizaciones o agresiones.

\section{EL CICLO DE LAS NECESIDADES. CERRAR UNA GESTALT INCONCLUSA}

El cierre de una gestalt inconclusa implica completar el ciclo de las necesidades, cerrar aquello que se ha quedado interrumpido en un momento dado. Muchas veces estas heridas sin sanar se manifiestan en síntomas físicos, emocionales o mentales. Tener la oportunidad de actualizar los síntomas sobre la hoja de papel o la obra, nos permite encontrar un medio para materializarlos y poder trabajar en su expresión e integración.

Abrir es más fácil que cerrar y a veces el cierre requiere tiempo. Este proceso nunca es lineal, sino que requiere el margen necesario para permitir a la persona avanzar y retroceder, explorar el nuevo terreno y tomar fuerzas para dar un pequeño 
paso adelante. La obra actúa como anclaje, como eje vertebrador del proceso de cambio. La creación en el propio proceso arteterapéutico es la que nos da las claves para ir conformando ese recorrido simbólico, ese camino de subidas y bajadas, lleno de obstáculos que aprendemos a salvar a través de un continuo diálogo internoexterno.

\section{TRANSFERENCIA Y CONTRATRANSFERENCIA}

En terapia gestalt no se entiende la transferencia y la contratransferencia tal y como la expresan otras corrientes como el psicoanálisis. No se niega el fenómeno en sí, aunque se trabaja desde otro lado.

Sabemos que los pacientes actualizan sus relaciones biográficas en el aquí y ahora terapéutico, que muchas veces identifican al terapeuta como al padre o la madre y que esto afecta a los sentimientos y conductas del terapeuta.

Todo se actualiza en el presente. Por lo tanto se pone la atención en lo que está pasando aquí y ahora, primando esa experiencia como situación correctora.

La transferencia del cliente se entiende en gestalt como proyecciones y la contratransferencia del terapeuta como la exploración deliberada y selectiva de sus propios sentimientos como motor del tratamiento.

Perls niega la base del fenómeno transferencial. Por ejemplo: No veo omnipotente al terapeuta porque así veía a mi padre, sino porque he alienado ese aspecto de mí y lo he puesto en el entorno, en este caso en el terapeuta. Sustituye así el concepto de transferencia por el concepto de responsabilidad (el paciente se desresponsabiliza de una parte de sí y la proyecta). El terapeuta no toma la responsabilidad del otro, sino que desvela su juego y lo frustra.

El terapeuta utiliza sus propios sentimientos y su resonancia afectiva de forma activa en la terapia.

La obra va desvelando este juego, unida al lenguaje corporal y a la palabra, generando un amplio abanico de recursos de los que nos servimos para dar dirección a nuestro proceso de creación de nosotros mismos. Es interesante no concebir este proceso solamente como "crecimiento", sino como "decrecimiento" personal, es decir, como desmontaje de nuestros esquemas e ideas previas y estáticas a cerca de nosotros, de la vida y de cómo nos manejamos en ella.

\section{Otros recursos en arteterapia gestalt}

El cuerpo en arteterapia gestalt es un elemento fundamental, no sólo como actor, sino como receptor de lo que se genera en el proceso arteterapéutico y como mediador-intermediario que nos acompaña en este tránsito de reencuentro con nosotros mismos.

Interesa la experiencia fenomenológica del paciente sobre su propio cuerpo, más que el movimiento y la expresión.

- En el estilo orgánico: lo corporal se enfoca fenomenológicamente, atendiendo a los mensajes que transmite la respiración, la postura, los gestos, la voz. 
El arteterapeuta acompaña, ampliando la conciencia con todos los medios de que dispone, remitiendo al paciente su propia experiencia corporal.

- En el estilo sistemático se incluyen técnicas corporales. El arteterapeuta coordina el trabajo corporal y luego elabora aquello que se movilizó.

En arteterapia es posible integrar el cuerpo desde estas dos vertientes. La persona, su cuerpo, su obra, como espacios que se interrelacionan y que son acompañados por la presencia del terapeuta. No son compartimentos fijos y estancos, sino aspectos que interactúan unos con otros, se complementan y se enriquecen mutuamente.

La gestalt es una experiencia viva y no un conjunto de técnicas. Pero se emplean muchas técnicas en forma de juegos que nos ayudan a activarnos, movilizar nuestros procesos internos y hacernos conscientes de nuestras emociones, sentimientos y conductas.

La finalidad es facilitar que las resistencias salgan a la luz, facilitar la toma de conciencia de sí mismo y facilitar un proceso de maduración, al pasar por momentos de bloqueos o situaciones fijadas y arraigadas en el cuerpo y en la mente.

En este sentido debemos estar alertas para no simplificar la experiencia y permitir que estas herramientas favorezcan el trabajo y no nos encasillen. De nuevo el trabajo personal del arteterapeuta está en ser consciente de sus recursos no sólo materiales, sino también internos para salir al encuentro de lo que emerge en cada aventura creativa, sin limitarnos a la técnica en sí. Muchas veces la falta de recursos del arteterapeuta lo lleva a agarrarse al uso del material, la técnica, las propuestas directivas que dificultan el flujo creativo de la experiencia. Es necesario trascender estos elementos e integrarlos como partes de un contexto mucho más amplio que es el arteterapia en sí mismo.

Por su carácter visual, el arteterapia tiene mucha similitud con las psicofantasías, aunque en arteterapia pasamos de visualizarlas a representarlas materialmente.

A través de la fantasía y de la creación, podemos indagar en nuestro mundo imaginario, materializando y transformando nuestras imágenes internas sobre nosotros mismos mediante el acto de crear. Pasamos de ser observadores a ser actores de nuestra propia obra-vida.

Dice Francisco Peñarrubia: "La finalidad de la conducción de fantasías es la ampliación de la autoconciencia, así como proponer al paciente vivenciarse en acción".

Los sueños son un elemento que se trabaja también en arteterapia gestalt. Conducen a la integración y son proyecciones y representaciones de los distintos aspectos de la personalidad del que sueña. También puede verse a través de él, el tipo de contacto que establece el soñante con los demás, sus angustias, temores y deseos. Son mensajes existenciales. Lo relatamos en primera persona y en presente y es importante prestar atención a las emociones que se generan, sensaciones corporales, etc., pudiendo integrar a través de su elaboración las diferentes partes de uno mismo. Así podemos ir del sueño a la realidad, establecer un diálogo entre sus partes representadas en la obra y favorecer la identificación con los diferentes elementos del 
sueño. Podemos representarlo colectivamente entre los miembros del grupo, actuarlo, revivirlo para actualizar la experiencia y favorecer así la toma de conciencia.

Lo transpersonal en gestalt se relaciona con la intuición, la creatividad, las experiencias-cumbre de las que hablaba Maslow, no necesariamente extraordinarias, sino ligadas a la vida cotidiana.

La espiritualidad de la gestalt se basa en la integración de polaridades, la influencia del zen, el continuo atencional y la meditación vipassana.

\section{EL ENCUADRE EN ARTETERAPIA GESTALT}

\section{La actitud terapéutica}

Dentro del encuadre o setting en Arteterapia gestalt podemos distinguir entre aspectos formales y no formales.

Dentro de los aspectos formales hemos de prestar atención al contrato terapéutico, la forma de pago, el espacio y el material, cuestiones básicas y muy generalizadas, aunque en gestalt tienen sus peculiaridades, como pueden ser el trabajo en el suelo y el uso de otros materiales complementarios como cojines, telas, música, objetos varios.

Con respecto a los aspectos no formales podemos destacar al grupo como unidad que acompaña y potencia el trabajo creativo y personal de cada uno, ofreciendo su escucha, su presencia, participando de forma activa y sirviéndonos de espejo. En el grupo se ven reflejados los diferentes aspectos de uno mismo con los que entramos en contacto.

Otro tema a considerar es la polémica directividad-no directividad. Hemos de tener en cuenta que todo proceso arteterapéutico serio ha de basarse en el respeto por la persona con la que trabajamos, sus tiempos, sus resistencias, su propio ritmo y necesidades. Y nuestra labor no es otra que la de acompañar y no la de dirigir en función de nuestras propias expectativas e ideas preestablecidas. La directividad se da cuando me pongo por encima del otro, cuando "impongo" mi propio ritmo y necesidades. El arteterapeuta se entiende en este contexto como acompañante que canaliza el proceso, arropa y apoya cuando es necesario y también confronta a la persona con sus juegos y manipulaciones, haciéndole ver a veces sus contradicciones y discursos ambiguos.

El contacto en arteterapia gestalt es directo y cercano, una relación Yo-Tú, donde se encuentran dos personas en una relación humana, aunque jerárquica. Esta jerarquía no tiene connotaciones de poder, sino de cargo. El arteterapeuta supuestamente debe haber transitado su propio proceso terapéutico para poder acompañar, escuchar, entender y facilitar el camino del otro. Ha de haber transitado su propio dolor, su miedo, su vacío, para tolerar el vacío del otro, desarrollar la escucha activa, estar atento. Ha de tener recursos personales y también prácticos, pero sin confundir los medios con el fin. 


\section{ARTETERAPIA GESTALT. CÓMO TRABAJAR CON NUESTRAS IMÁ- GENES INTERNAS}

"Lo-que-necesita-ser-pintado no se debe confundir con pintar lo que uno quiera, aunque eso puede coincidir en algún momento del proceso. Es más bien aprender a aceptar lo-que-quiere-ser-pintado. Con otras palabras, atender a la figura que quiere emerger, es aprender a retirarse." Katharina Widmer.

El punto de partida puede ser crear a partir de un tema o necesidad concreta, a partir de un color, un gesto, de sensaciones corporales. O construir a partir de una imagen previa. Al principio una simple excusa puede servir de detonante para arrancar. Y de este modo, una imagen se va sucediendo a la otra, enlazando historias que tienen que ver con la propia persona, con el hilo de su vida, sus necesidades más apremiantes que se van concretando en el hecho de crear. No se trata de hacer algo concreto, sino de permitir que aflore la imagen que espera, dar espacio a la obra, sin precipitarse.

No debemos perder de vista el contrato terapéutico y los fines del trabajo, asumiendo que es la persona que crea la que marca su propio ritmo. A veces es necesario asumir que el tiempo y una buena orientación del proceso darán sentido y coherencia a imágenes aparentemente distantes e inconexas. Es en la escucha activa, donde ponemos todos nuestros sentidos a disposición de la persona, tolerando sus silencios, su no saber, su incapacidad para asimilar la obra como propia en un primer momento.

En la obra no solamente es importante lo que se crea, sino cómo se crea. Si prestamos atención a la relación que establece la persona con su obra, a sus reacciones, sus gestos, sus expresiones, las interrupciones de la tarea, tendremos más pistas acerca de sus necesidades y sus limitaciones, los mecanismos que emplea para desviar su atención de la toma de conciencia de lo que nos ocupa.

En el proceso debemos mantener un rumbo, una dirección, apuntar a la relación entre lo que ocurre en el espacio terapéutico y la manera de vivir de esa persona, estableciendo un paralelismo entre la manera de crear y la manera de abordar la propia vida. Así lo elaborado en el taller va trascendiendo poco a poco a su realidad cotidiana.

Es importante y valioso sobre todo al iniciar el proceso, señalar lo obvio, la pincelada, el uso del material, la relación con la obra y los materiales. A veces simplemente se trata de enfocar una imagen lejana o intervenir sobre una pequeña parte del trabajo.

No es lo mismo una horizontal, una vertical que una diagonal. No es igual distribuir una composición en forma curva, cuadrada o triangular. Seguir una dirección claramente marcada que ha quedado cortada por el límite del papel puede servirnos para continuar explorando e ir más allá. El cuerpo y el movimiento también nos dan pistas, si es exagerado, suave, controlado o intermitente. Podemos jugar con la perspectiva, con el punto de vista desde el que se aborda la obra. 
No sólo los espacios ocupados son importantes. También lo son los vacíos, las ausencias.

Se trata en definitiva de señalar lo obvio para seguir la pista de lo más oculto, lo que asoma tímidamente y que busca ser tenido en cuenta.

\section{COMO CONCLUSIÓN}

La gestalt es una corriente muy rica, cercana, muy humana. No es sólo una manera de trabajar, sino una manera de vivir, de ser y estar en la vida.

Podemos aplicar los planteamientos de la gestalt en nuestro día a día, nuestras rutinas, nuestras relaciones. Así la gestalt se hace vida, aportándonos una nueva forma de sentir en la búsqueda de lo que realmente somos.

El arteterapia gestalt nos permite enlazar creativamente con nosotros mismos, a veces de manera sutil, otras de manera más directa y clara.

Darnos la oportunidad de sentir, de explorar, de expresar; replantearnos nuestra existencia y nuestros vínculos afectivos. Todo ello buscando una vida más plena, más armónica, más auténtica, dejando salir nuestra creatividad innata y nuestro potencial como seres que exploran su humanidad, más allá de los roles o estereotipos en los que a menudo nos vemos encasillados. Más que de construir, se trata de desmontar nuestros esquemas y ampliar la mirada, descubrir nuevas posibilidades que se hacen presentes a través de la obra y que sea ella quién nos guíe en la búsqueda. Vivimos con la intención de afianzar, de ampliar, de levantar altas torres de logros y éxitos, de certezas. Y sin embargo la experiencia en arteterapia nos lleva a un punto muy distinto: a reconocer que de lo ambiguo, lo indefinido, lo oscuro, lo doloroso, podemos renacer con más brillo; que nuestras imágenes internas son mensajes existenciales que nos dan la oportunidad de tirar del hilo y dialogar con nuestra vulnerabilidad y nuestras sombras. Y reconciliarnos con nosotros mismo es el primer paso para crecer y avanzar. El arteterapia gestalt nos facilita esta experiencia. Sólo hace falta que asumamos el riesgo que implica vivir creativamente. 


\section{REFERENCIAS BIBIOGRÁFICAS}

BORJA, G. (2008). La locura lo cura. Manifiesto psicoterapéutico. Vitoria-Gasteiz. Ediciones La llave.

KLEIN, JP. (2006). Arteterapia. Una introducción. Barcelona. Octaedro.

MARTÍN, A. y VÁZQUEZ, C. (2005). Cuando me encuentro con el Capitán Garfio... (NO) me engancho. Bilbao. Desclée de Brouwer.

MARTÍN, A. (2009. $5^{\text {a }}$ edición). Manual práctico de psicoterapia gestalt. Bilbao. Desclée de Brouwer.

PEÑARRUBIA, F. (2008. $2^{\mathrm{a}}$ edición). Terapia Gestalt. La vía del vacío fértil. Madrid. Alianza editorial,

ROGERS, C. (1978. $17^{\mathrm{a}}$ edición) El proceso de convertirse en persona. Buenos Aires, Paidos.

STEVENS, JO. (2003. 24a edición) El darse cuenta. Sentir, imaginar, vivenciar. Mexico, Cuatro vientos.

WIDMER, K. (2006). Pintura-Terapia gestáltica. Imágenes del alma. Madrid. Mandala Ediciones. 